\title{
MATERNIDADE PARA QUEM? MULHERES NEGRAS, CUIDADO COLONIAL E DROGAS ${ }^{*_{1}}$
}

Rachel Gouveia Passos

Jessica Taiane da Silva

\section{Introdução}

Em março de 2020, o Jornal Agência Pública publicou a seguinte manchete: "Nas maternidades, a dor também tem cor" ${ }^{\text {" }}$. O texto apresenta experiências vivenciadas cotidianamente por mulheres negras nas maternidades e, também, resgata o ponto central da questão de iniquidades em saúde no Brasil. Dentre os depoimentos, está o de Michele Monteiro, 42 anos, negra, que implorava por anestesia e pela cesárea e, durante o intervalo das intermináveis contrações, ouviu da equipe: "Mas como? Você teve quatro filhos, dois normais (...) por que você não tenta mais um? Você é forte, vai conseguir."

Em outubro de 2020, Maiara Oliveira da Silva e sua família, juntavam dinheiro para descobrir o sexo do bebê que a jovem esperava. Entretanto, o sentimento de expectativa pela chegada do novo membro da família foi convertido em luto e preocupação após a gestante, de 20 anos, negra, ser atingida ${ }^{3}$ na barriga por uma "bala achada" ${ }^{4}$ durante uma operação policial no Complexo da Maré, Zona Norte do Rio de Janeiro. O bebê não resistiu e Maiara ficou em estado grave por semanas.

"Arruma as coisas do seu filho que o Conselho Tutelar está vindo buscar ele daqui a 30 minutos." Yanca Miranda, 21 anos, negra, ouviu essas palavras da assistente social enquanto amamentava seu bebê na sala da maternidade. Durante os 19 dias que Yanca esteve internada no hospital, ninguém a alertou sobre a possibilidade de seu filho ser levado para um abrigo. "Disseram apenas que eu ia passar uns dias no hospital em observação porque estava escrito no meu cartão de pré-natal que eu era usuária de drogas.", disse a jovem.

O discurso social acerca da maternidade pressupõe a existência de um vínculo natural entre mãe e filho desde antes do nascimento, espera-se da mulher o "instinto nato da maternagem", ou seja, do cuidado para com o recém-nascido. No entanto, os casos apresentados retratam as violências experienciadas por mulheres negras durante o momento maternal, expressas pela violência obstétrica que atinge seu corpo, pela "bala achada" que atravessa o seu ventre ou pelo sequestro do Estado, em casos de retiradas compulsórias de bebês. Logo, mulheres negras são a todo momento impedidas de exercerem a maternagem (PASSOS, 2021).

Nesse sentido, salientamos que essas violências têm como ponto comum o racismo que está imbricado em todas as relações sociais e institucionais, tendo como alvo a população negra. Assim, denunciamos que há em curso um movimento de controle e extermínio dos corpos e

${ }^{*}$ DOI- 10.29388/978-65-81417-27-7-0-f.78-92

1 O presente capítulo compõe o Projeto de Pesquisa e Extensão Luta Antimanicomial e Feminismos.

2 Disponível em: https://apublica.org/2020/03/nas-maternidades-a-dor-tambem-tem-cor/. Acesso realizado em: 13 mai. 2021.

3 Disponível em: https://extra.globo.com/casos-de-policia/familia-de-gravida-baleada-na-mare-juntava-dinheiro-para-exameque-descobriria-sexo-do-bebe-24717913.html. Acesso realizado em: 13 mai. 2021.

${ }^{4}$ Texto publicado no jornal Folha de São Paulo, segunda-feira, 14 de novembro de 1994, pelo jornalista Josias de Souza. Disponível em: https://www1.folha.uol.com.br/fsp/1994/11/14/opiniao/5.html. Acesso realizado em: 05 mai. 2021.

5 Disponível em: https:/ /apublica.org/2020/03/nas-maternidades-a-dor-tambem-tem-cor/. Acesso realizado em: 13 mai. 2021. 
subjetividades negras, devido à noção de sujeito perigoso (PASSOS, 2019). Para Almeida (2014), esse fenômeno da violência está relacionado ao processo de desumanização das vidas negras, que se conforma como parte do racismo estrutural e se expressa por meio da violência e do racismo institucional. Nesse sentido, mesmo após 132 anos, as mulheres negras que desejam ou já são mães, que pertencem a quarta, quinta ou sexta geração pós "abolição" da escravidão, ainda experienciam as barreiras impostas pelo racismo presente na sociedade e nas instituições.

De acordo com a pesquisa "Nascer no Brasil: Pesquisa Nacional sobre Parto e Nascimento" (LEAL et al., 2017), observa-se que as gestantes negras possuem maior risco de pré-natal inadequado, de menor tempo de consulta, de não serem vinculadas a uma maternidade, de peregrinarem por mais de uma maternidade para ter o seu parto, de receberem menos anestesia local quando submetidas a episiotomia. Essas disparidades durante o pré-natal e o parto são expressão do racismo estrutural.

Torna-se necessário salientar que a desigualdade no atendimento e na percepção social sobre a população negra não é uma questão somente da saúde, ela também pode ser localizada em outras áreas e instituições sociais, seja pela via da culpabilização dos indivíduos pela sua condição social, seu modo de ser e estar no mundo, pela alta tutela que não respeita a autonomia dos usuários, e também pelo processo de manicomialização através da assistência social (DUARTE, 2013). Destacamos aqui a complexidade que envolve o tema da maternagem negra, principalmente, quando associado ao uso prejudicial de drogas o que acaba envolvendo as diversas políticas públicas.

Portanto, no presente capítulo objetivamos problematizar a idealização do amor materno e a naturalização da imposição de um modelo de mãe, o que é atravessado pelas relações de gênero, raça e classe. Nesse sentido, dividiu-se em dois tópicos a discussão: no primeiro momento tratamos do mito do amor materno e o conceito de cuidado colonial (PASSOS, 2020; 2021) como uma reatualização da captura da maternagem negra através de discursos e práticas colonialistas. Em seguida, problematizamos a situação das mulheres negras que fazem uso prejudicial de álcool e outras drogas e têm seus filhos retirados compulsoriamente como estratégia de controle dos corpos por parte do Estado, negando as potencialidades e autonomia dessas mulheres. Por fim, não pretendemos encerrar as discussões, mas sim apresentar inquietações e reflexões acerca da maternagem negra e o direito à convivência familiar.

\section{Quem pode maternar? Mulheres negras e o cuidado colonial}

Para que haja a reprodução, a continuidade e existência da humanidade, é preciso que ocorra a cooperação entre os indivíduos, assim, partimos do entendimento que o cuidado é uma necessidade ontológica do ser social. Nessa perspectiva, existem alguns indivíduos que não podem ou não conseguem suprir suas necessidades ontológicas primárias, o que os torna "dependentes" de outrem. Assim, segundo Passos (2020; 2016), o cuidado pode ser definido como essa relação de interdependência entre os seres humanos, uma vez que, há a necessidade do indivíduo para existir e a ação para ser suprida.

O modo de produção vigente é composto por múltiplos grupos sociais envolvidos em relações sociais diversas, desiguais e hierárquicas. A divisão sexual do trabalho é a forma de divisão do trabalho social resultante das relações sociais de gênero e tem por características a destinação prioritária dos homens à esfera produtiva e das mulheres à esfera reprodutiva, desta 
forma, a sociedade se utiliza dessa diferenciação para hierarquizar as atividades produtivas e reprodutivas (KERGOAT, 1996). De acordo com Passos (2020), as maneiras de provimento e viabilização do cuidado são alteradas de acordo com o desenvolvimento das forças produtivas e com o modo de reprodução social. Assim, no modo de produção capitalista, e em sua divisão social e sexual, o trabalho do cuidado ficou a cargo das mulheres e vinculado à determinada "essência feminina" (PASSOS, 2017).

Considerando-se que a categoria "mulher" não pode ser compreendida a partir de uma noção universal e homogênea, precisamos destacar que essa essencialização do feminino, o papel de boa esposa, boa mãe, mulher dócil e amável não contemplará um determinado grupo de mulheres que se encontram na intersecção dos marcadores sociais da diferença e, aqui, destacamos as mulheres negras. Segundo Passos (2017), essa sobreposição dos marcadores de gênero, raça e classe, vai levá-las a permanecer na execução do trabalho doméstico e de cuidados, não só como uma relação de extensão da esfera reprodutiva, mas estabelecida e demarcada pela colonialidade, pelo patriarcado e pelo racismo.

Cabe recordar que em 1851, Sojourner Truth, ex-escravizada norte-americana que se tornou oradora, fez um discurso intitulado "E eu não sou uma mulher?" na Convenção dos Direitos das Mulheres em Ohio:

Aquele homem ali diz que é preciso ajudar as mulheres a subir numa carruagem, é preciso carregar elas quando atravessam um lamaçal e elas devem ocupar sempre os melhores lugares. Nunca ninguém me ajuda a subir numa carruagem, a passar por cima da lama ou me cede o melhor lugar! E não sou uma mulher? Olhem para mim! Olhem para meu braço! Eu capinei, eu plantei juntei palha nos celeiros e homem nenhum conseguiu me superar! E não sou uma mulher? Eu consegui trabalhar e comer tanto quanto um homem quando tinha o que comer - e também aguentei as chicotadas! E não sou mulher? Pari cinco filhos e a maioria deles foi vendida como escravos. Quando manifestei minha dor de mãe, ninguém, a não ser Jesus, me ouviu! E não sou uma mulher? (TRUTH, 1851 apud MOURA, 2009)

O discurso de Truth já denunciava a diferença crucial entre a condição das mulheres negras e brancas. Enquanto àquela época mulheres brancas lutavam pelo direito ao voto e ao trabalho, mulheres negras lutavam para serem consideradas humanas. E essa diferença central acompanha as mulheres negras até os dias atuais e, tem suas manifestações particulares na realidade brasileira.

$\mathrm{Na}$ experiência brasileira, assentada em um sistema cisheteropatriarcal, racista e colonialista, ocorreu a imposição às mulheres negras de terem o papel de protagonistas do trabalho invisível e subalterno que diz respeito à esfera reprodutiva da vida, ou seja, lavar, cozinhar, passar, executar serviços de limpeza, e também, cuidar. Assim, de acordo com Passos (2017):

Essa essencialização do feminino, para a mulher negra, tende a ser explorada de forma avassaladora e perversa, antes pelo senhor de escravos (pela exploração sexual, para servir na Casa Grande, como ama de leite), agora pela mercantilização do trabalho doméstico e de cuidados, via mercado privado ou 
pelas políticas públicas. Podemos perceber que as atribuições permanecem as mesmas, só que em um cenário completamente diferente (PASSOS, 2017, p. 88).

Segundo González e Halsenbalg (1982), a raça, como atributo social e historicamente elaborado, funciona como um dos critérios mais importantes na distribuição de pessoas na hierarquia social. Destacamos que há, no "cuidar", uma contradição singular que persegue as mulheres negras desde o período colonial. Note que, se por um lado, estas mulheres supostamente possuiriam o "dom do cuidado", seja para o lar ou para com o outro, como se pode encontrar nos anúncios de jornais que circulavam nos anos de 1800: "Vende-se uma bonita negrinha de 16 annos, cose muito bem, engomma, lava e cozinha; na rua de S. Pedro, $n^{\circ} 161^{6 "}$ ". Por outro lado, estas mesmas mulheres nunca tiveram estímulo social para cuidarem de si, de seus lares ou de suas próprias famílias. Isto nos traz à recordação o quadro "Mãe preta", de 1912, onde uma mulher, negra e jovem, sentada no chão, amamenta um bebê branco ao colo enquanto olha com um ar melancólico para um neném negro que está deitado ao lado, e a criança atenta à mãe, como quem espera a sua vez de tomar do leite materno. Portanto, este é o retrato da mãe preta brasileira.

A subalternização de mulheres negras e sua desvinculação ao direito a maternagem está intrinsecamente vinculada ao passado escravista brasileiro. As mulheres negras escravizadas foram marcadas pelo trabalho forçado, por violências físicas, sexuais, além de terem seus filhos retirados à força e vendidos como potencial força de trabalho. Segundo bell hooks (1990), mesmo sem oferecer os meios necessários para uma gestação saudável, havia naquele momento um incentivo à reprodução da população escravizada, visto que, a riqueza era medida pela quantidade de pessoas escravizadas que cada um possuía. Assim:

A procriação era opressiva para todas as mulheres negras escravas férteis. Subnutridas, sobrecarregadas as mulheres raramente estavam em condições físicas que lhes pudessem permitir um parto seguro e fácil. As repetidas gravidezes sem cuidados apropriados resultavam em numerosos abortos e mortes (HOOCKS, p. 31).

De acordo com hooks (1990, p.14), o sexismo institucionalizado, estabelecido por uma sociedade patriarcal, formou a base da estrutura social nas Américas, em conjunto com o imperialismo racial. Assim, a maternidade foi um aspecto bastante complexo na vida de mulheres escravizadas. No entanto, a exploração dos corpos das mulheres negras e a restrição de sua autonomia sexual e reprodutiva não se limitaram ao contexto escravista.

No atual contexto brasileiro, as mulheres negras ainda têm o direito à maternidade negado, além de serem incessantemente desestimuladas a exercerem a maternagem desde o momento da gestação. As iniquidades vivenciadas por elas têm como pano de fundo o racismo institucional presente nas unidades e equipes hospitalares que carregam em si diversas crenças fundamentadas no racismo científico do final do século XIX, justificadas na ideia de que mulheres negras aguentam mais a dor. Portanto, não precisariam de anestésicos e nem mesmo possuiriam intelecto suficiente para terem conhecimento pleno dos efeitos colaterais de certos procedimentos e medicações, como anticoncepcionais com altos níveis de hormônios que podem causar síndrome de ovários policísticos, dentre outras crenças incabíveis nos dias atuais.

${ }^{6}$ Jornnal do Commercio, quinta feira, 4 de janeiro de 1872; e quarta feira, 10 de abril de 1872. 
Com a violência obstétrica sofrida por mulheres negras durante o pré-natal, parto e pós parto, seus filhos também conhecem a dor inerente ao racismo ainda nos primeiros segundos de vida. Estudos realizados pela George Mason University (2016) revelam que recém-nascidos negros têm maior chance de sobrevivência quando o médico do hospital responsável por eles também é negro. Quando atendidos por um médico branco, os bebês negros têm aproximadamente três vezes mais probabilidade de morrer do que bebês brancos. Logo, ao deslocarmos a análise para a realidade brasileira, a situação se agrava ainda mais, visto que, a quantidade de médicos negros é menor que nos EUA.

Mulheres negras são vítimas do controle de seus corpos, quer seja pela dimensão da fertilidade, ou pela punição ao engravidar sem a "permissão" do Estado. E não é à toa que Sergio Cabral, ex-governador do Rio de Janeiro, propôs a legalização do aborto como forma de conter a violência no estado e afirmou que as favelas são "fábricas de produzir marginais" da famigerada guerra às drogas esconde uma política genocida contra a população negra, pobre e moradora das favelas e periferias, independentemente de envolvimento com o crime, como é alegado em grande parte das mortes provocadas por agentes do Estado ${ }^{8}$. É possível analisarmos a violência institucionalizada na ação policial contra determinados grupos sociais através do conceito de necropolítica (MBEMBE, 2018), uma vez que o racismo institucionalizado nas políticas de Estado determina as condições de aceitabilidade de quem vive e morre no cenário neoliberal.

Conforme dados do IPEA (2019), filhos e companheiros de mulheres negras são alvos recorrentes da violência de Estado e do racismo institucionalizado. De acordo com o Atlas da Violência (IPEA, 2019), em 2017, mais de 75,5\% das vítimas de homicídio eram jovens e negros. Entre 2007 e 2017, a taxa de pessoas negras mortas subiu 33\%. A mortalidade de não negros subiu apenas 3,3\%. Nesse sentido, as mulheres negras, familiares desses jovens e em sua maioria suas mães, são o grupo que mais sofre com os impactos desta realidade, e esse fato gera diversos tipos de adoecimentos físicos, psíquicos e metais (ARAÚJO, 2019).

Mas é justamente aquela negra anônima, habitante da periferia, nas baixadas da vida, quem sofre mais tragicamente os efeitos da terrível culpabilidade branca. Exatamente porque é ela que sobrevive na base da prestação de serviços, segurando a barra familiar praticamente sozinha. Isto porque seu homem, seus irmãos ou seus filhos são objeto de perseguição policial sistemática (GONZÁLEZ, 1984, p.231).

\footnotetext{
7 Segundo o ex-governador, "interrupção da gravidez tem tudo a ver com a violência pública". Disponível em: https://g1.globo.com/Noticias/Politica/0,,MUL155710-5601,00-

CABRAL+DEFENDE+ABORTO+CONTRA+VIOLENCIA+NO+RIO+DE+JANEIRO.html. Acesso realizado em: 14 mai. 2021.

${ }^{8}$ Há um amplo debate sobre os crescentes índices de "autos de resistência", que são ocorrências de homicídio contra civis cometido em situação de suposto confronto, com a presunção de legítima defesa, conforme previsto no artigo 121, c/c, 73, II, do Código Penal Brasileiro. Existe um processo em tramitação na câmara chamado "excludente de ilicitude" que prevê que em caso de morte, em vez de o policial responder a processos que averiguarão se ele cometeu homicídio sem justificativa plausível, estará sempre preestabelecido que agiu em legítima defesa, assim, não haverá investigação. Ora, visto que auto de resistência já é utilizado como estratégia para isentar-se do homicídio causado, uma vez essa proposta sendo aceita, será como uma licença para matar. Indicamos o documentário Auto de resistência (2018).
} 
Além disso, há um índice crescente de crianças e adolescentes mortos por "balas achadas", seja durante o recreio na escola, seja brincando no portão de casa, seja dentro de uma kombi junto com a mãe ou dentro da própria casa. A Polícia Civil afirma que crimes com óbitos de crianças são prioridade, mas o questionamento a ser feito é: quais crianças são prioridade?

Nesse sentido, salientamos que os casos que têm como protagonistas pessoas negras tendem a gerar menor comoção social que as violências sofridas por pessoas brancas. Em outros termos, numa sociedade estruturalmente fundada no racismo enquanto mecanismo de um sistema político de dominação, como o Brasil, as "formas contemporâneas que subjugam a vida ao poder da morte" (FOUCALT, 2010) estão definidas a partir de duas ideias que se complementam: a primeira, que existem diferentes raças humanas; e a segunda, que existem raças humanas que são inferiores às outras. Se considerarmos que, até bem pouco tempo, negras e negros nem eram vistos como seres humanos, a naturalização de sua dor significa a perpetuação da desumanização dessas pessoas e essa desumanização promove a coisificação do não ser, ou seja, animaliza, coisifica e objetifica, o que significa que pode ter sua existência exterminada (FANON, 2008), e isso justifica a indiferença diante de seu sofrimento.

No entanto, há de se destacar que existe uma protagonista comum neste cenário de dor e sofrimento, seja sofrendo no próprio corpo através de violência doméstica, violência obstétrica, sexismo, racismo e tantas outras opressões, ou sofrendo junto pelas dores de seus filhos e companheiros, seja nas filas de visitação dos presídios e unidades de medida socioeducativas, seja ao vê-los assassinados por agentes do Estado. No final, são as mulheres negras que enterram seus mortos.

Acredito que as mulheres negras estão profundamente acostumadas com a tragédia. Nós esperamos a tragédia. A morte não é uma estranha em nossas vidas, em nossos mundos. Perdemos nossos pais devido a hipertensão e ataques do coração; perdemos nossos maridos e amantes vitimados pela violência policial; perdemos nossos filhos nas prisões ou no tráfico de drogas (DAVIS, B., 2006, p. 108-109).

Ao realizarmos uma interlocução com o campo da saúde mental, podemos citar o papel central da Psiquiatria no controle do corpo das mulheres, as teorias de hierarquização racial e de gênero que surgiram durante os séculos XVIII e XIX justificaram por muito tempo as alegações de que mulheres eram naturalmente "instáveis e mais passíveis ao enlouquecimento". Assim, utilizavam-se de práticas extremamente moralistas como forma de conter, medicalizar e isolar os corpos lidos como "desviantes". (PEREIRA, 2019). Ainda hoje, mesmo diante dos avanços que obtivemos a partir da militância pela Reforma Psiquiátrica, se observa um grande fluxo de encaminhamentos para as instituições totais (NORO, 2021).

E assim, ao aparecer em cena no campo da saúde mental, todo esse sofrimento passa por um processo de abstração de sua causa maior que reduz todas as dores causadas pelo racismo e sexismo a um mero sintoma, seguido de medicalização, psiquiatrização e patologização desses corpos e subjetividades, causando a individualização de questões que são coletivas e estruturais. Desta forma, ao partirmos de um conceito ampliado de saúde mental, compreendemos que ela vai além de um acompanhamento especializado, mas também no bem estar diário, no prazer, na convivência familiar, nas relações sociais, no acesso aos serviços de saúde, serviços assistenciais, 
acesso a um trabalho decente ${ }^{9}$, alimentação, saneamento básico. Logo, a falta de acesso a tudo isso, além das diversas expressões de violências que atravessam os corpos de mulheres negras, são fatores que causam ou agravam o adoecimento psíquico.

Diante do exposto, resgatamos a indagação realizada no início: Quem pode (e é estimulada a) maternar? Quem são as mulheres consideradas dóceis, amáveis e frágeis? E, por outro lado, conforme aponta Kilomba (2019), quem estaria na posição de outridade e localizada não lugar? No próximo tópico nos debruçaremos sobre a negação da maternidade por parte das mulheres negras que fazem/fizeram uso prejudicial de álcool e/ou drogas e tiveram seus filhos retirados por não serem identificadas como mães ideais.

\section{3. “Meus filhos não são meus!”: Drogas e maternidade}

De acordo com o que foi exposto anteriormente, podemos analisar que as percepções e crenças sobre amorosidade, cuidado e maternagem, criados e sustentados pelo mito do amor materno, não abarcam as mulheres negras, uma vez que essas não têm direito à maternar, acompanhar de perto o desenvolvimento de seus filhos e quando não desejam tornar-se mães, se veem completamente destituídas da autonomia sobre seu próprio corpo. Nesse sentido, se as mulheres negras são violentadas, culpabilizadas e exoneradas do papel de mãe, aquelas que estão em situação de rua ${ }^{10} \mathrm{e} / \mathrm{ou}$ fazem uso de álcool e outras drogas estarão numa posição ainda pior. Estas são frequentemente rotuladas como negligentes, ligadas aos estereótipos de periculosidade e de fracasso, ou seja, a mãe "anormal".

A maternidade posta em um lugar romantizado e a forma como as políticas sociais são construídas a partir dessa idealização nos levam a refletir sobre esse tipo de sociabilidade que não consegue enxergar as mulheres para além da sua capacidade reprodutiva e impõe a maternidade desconsiderando todas as dificuldades decorrentes da criação de um filho sem o suporte necessário. Essa lógica acaba por desresponsabilizar o Estado e sobrecarregar as mulheres, que em sua maioria, são as principais responsáveis pelo cuidado da família (MIOTO, 2008). Entretanto, de acordo com Napoleão (2020), no caso de mulheres que estão em situação de rua e/ou fazem uso de drogas, a maternidade carrega a ideia de que se trata de uma sexualidade errada, suja e irresponsável, assim, aciona a necessidade de intervir sobre aquele corpo, sob a justificativa do cuidado e proteção - da criança. E as mulheres permanecem ali, no limite entre o cerco e o cuidado.

Nesse caminho, buscamos analisar as ações assistenciais de (não) cuidado e (des)proteção social viabilizadas pelo Estado burguês como resposta à situação de mulheres negras mães, que estão em situação de rua e/ou fazem uso prejudicial de drogas, visto que, no cenário contemporâneo, fica muito evidente o processo de individualização e subjetivação das necessidades (PASSOS, 2017), e que essas ações podem determinar o futuro dessas mulheres.

Partindo do pressuposto da existência de um vínculo "natural" entre mãe e filho desde antes do nascimento, espera-se da mulher o "instinto nato" da maternagem, ou seja, do cuidado

\footnotetext{
9 O Trabalho Decente, conceito formalizado pela Organização Internacional do Trabalho (OIT) em 1999, sintetiza a sua missão histórica de promover oportunidades para que homens e mulheres possam ter um trabalho produtivo e de qualidade, em condições de liberdade, equidade, segurança e dignidade humana, sendo considerado condição fundamental para a superação da pobreza, a redução das desigualdades sociais, a garantia da governabilidade democrática e o desenvolvimento sustentável (OIT, p. 5., 2012).

${ }^{10}$ A expressão tem como finalidade descontruir o estigma que essa população carrega e introduzir a ideia de que estar na rua é algo transitório e provisório, portanto, passível de modificação, mesmo com as barreiras macropolíticas existentes nesse cenário.
} 
para com o recém-nascido (OLIVIO et al., 2011). Nesse sentido, cabe salientar que há uma dualidade na interpretação da maternidade, uma vez que algumas mulheres serão vistas como boas mães e outras como anormais (BADINTER, 1985). Assim, ações de instituições como as da saúde, assistência social, saúde mental e judiciário, visualizado a partir de uma concepção restrita de saúde e sem considerar a questão de saúde pública, serão orientadas pela ótica da dualidade, onde mães que fazem uso prejudicial de drogas são identificadas como anormais e sem recuperação.

A necessidade de discorrer sobre este tema deve-se a quantidade alarmante de bebês que são encaminhados compulsoriamente as unidades de reinserção social (URS) ao receberem alta nas maternidades públicas do estado e, em contrapartida, o desamparo vivenciado por estas mães. Dados do Levantamento Nacional das Crianças e Adolescentes em Serviço de Acolhimento (ASSIS; FARIAS, 2013) apontam que o principal motivo de acolhimento é a negligência familiar (40,6\%), e o segundo maior é consumo de psicoativos por parte dos responsáveis (19,5\%). Entretanto, pode haver uma diferenciação nos dias atuais, pois tais dados são referentes aos anos de 2009 e 2010. De acordo com dados do Sistema Nacional de Adoção e Acolhimento (CNJ, 2021), 14.786 crianças encontram-se acolhidas, no entanto, não há especificações sobre a natureza do acolhimento. Nesse sentido, a escassez de dados referentes ao acolhimento de recém nascidos de mulheres que se encontram em algum nível de vulnerabilidade, seja social ou pelo consumo de drogas, favorece a invisibilização da importância da criação de políticas sociais que garantam os direitos dessas mulheres e crianças.

Nessa perspectiva, a política implementada visa uma proteção dissimétrica legalizada, ou seja, ao separar o filho da mãe, esta recomendação adotada de forma cada vez mais frequente, protege a criança e sentencia a mulher pela suposta incapacidade de cuidar de seu filho. Nesse sentido, pressupomos que a falta de políticas que atendam integralmente essas mulheres, também correspondem a uma estratégica política.

O Estado que alega proteger acaba promovendo violações que reafirmam a punição e o extermínio dos corpos e comportamentos negros. É nesse processo que pretendemos abordar o cuidado colonial que reatualiza a captura da existência negra através dos discursos e práticas colonialistas. Além disso, abordaremos acerca da lógica manicomial e o extermínio da existência negra, entendendo-a como uma estratégia que se perpetua para além dos muros institucionais e que compõe a sociabilidade brasileira. (PASSOS, 2019. p. 117)

É necessário salientar que há um crescente movimento de mulheres que evitam realizar o acompanhamento obstétrico durante a gestação, e criam alternativas, seja realizando o parto em outra cidade ou até mesmo em suas residências, mesmo com pouquíssimo ou nenhum recurso. Uma vez que, buscar ou aceitar atendimento significa passar a existir e assim, documentar sua existência, gerar registros e possivelmente o rastreamento de seu paradeiro, ficando assim exposta ao risco da violência que é a perda de seus filhos.

Conforme o Estatuto da Criança e do Adolescente (ECA, 1990), a retirada de crianças de suas famílias será sempre excepcional e provisória, no entanto, este documento fundamental para a defesa das crianças, aqui, tem sido apropriado e utilizado como instrumento para negar o direito às mulheres. O estigma da maternidade vulnerável faz com que o abrigamento seja a primeira opção nesses casos. Dessa forma, o direito de tentar exercer a maternagem é 
completamente negado a estas mulheres, o que as torna ainda mais vulnerabilizadas, e ainda há casos em que a criança é adotada antes mesmo de recorrerem ao suporte da família extensa.

Estas experiências tornaram-se cada vez mais frequentes após recomendações implausíveis advindas da Vara de Infância e da Juventude de Belo Horizonte. No entanto, tais ações não se restringem aos municípios em que há estas orientações, são práticas recorrentes em muitos outros lugares. Tais medidas determinam que profissionais de saúde devam comunicar à justiça o nascimento de bebês cujas mães, ou até mesmo os neonatos, estivessem em "situação de grave risco, inclusive em virtude de dependência química ou trajetória de rua" (CRESS, 2017).

Diversos movimentos sociais reivindicam a criação de diretrizes e fluxos que visem a atenção integral à saúde das mulheres em situação de rua e/ou usuárias de substâncias psicoativas e seus filhos, de modo que a avaliação das condutas seja feita caso a caso, respeitando as singularidades existentes. No entanto, devemos reconhecer que no cotidiano profissional mediado por sua inerente complexidade e disputas ético-políticas -, recomendações, por melhores que sejam, não são suficientes para produzir os enfrentamentos necessários para defesa dos direitos das mães e das crianças. Assim, a atuação profissional poderá construir pontes ou barreiras de acesso, a depender de suas concepções e valores profissionais, pessoais, morais e éticos. $\mathrm{E}$, infelizmente, os dados mostram que as ações têm sido voltadas para um julgamento moral sobre quem tem e quem não tem direito de ser mãe, sendo autorizado o emprego da violência contra "uma vida que não vale a pena" em nome de outra a ser supostamente protegida.

As relações de gênero, raça e classe criaram ao longo de toda a história relações de acesso e/ou de opressão, o consumo de drogas por mulheres é aqui compreendido como uma alarmante questão de saúde pública que denuncia sintomas de um mal-estar social ancorado nas relações sociais desiguais (BARBOSA, 2017). No que se refere ao imaginário social sobre o uso de substâncias psicoativas, nota-se que a droga vem antes da própria mulher, da situação dela, mesmo que o uso tenha sido decorrente de suas vivências e opressões vividas, o que reforça as estruturas da exclusão, do racismo e das iniquidades de gênero.

Dito isso, destacamos que apesar destas mulheres possuírem algumas vivências aproximadas e similares, existem pontos centrais que as diferenciam e atravessam suas formas de serem e estarem no mundo. A categoria "mulher" não pode ser analisada de maneira engessada, sem considerar suas particularidades e marcadores de raça, classe, sexualidade, território, entre tantas outras diferenciações. Assim, ressaltamos que a interseccionalidade se configura enquanto uma ferramenta indispensável para refletirmos sobre como as opressões e explorações vivenciadas afetam diretamente nas condições de vida e, consequentemente, de saúde física e mental dessas mulheres. E, por sinal, quem são elas?

De acordo com o IBGE (2009), a população brasileira é composta por 50,7\% de pretos e pardos. Dados mostram que essa população possui os menores índices de escolaridade e renda, principalmente, quando comparadas aos brancos: $31,1 \%$ dos brancos frequentam o ensino superior, enquanto apenas $13,1 \%$ dos jovens negros, além do rendimento médio mensal que da

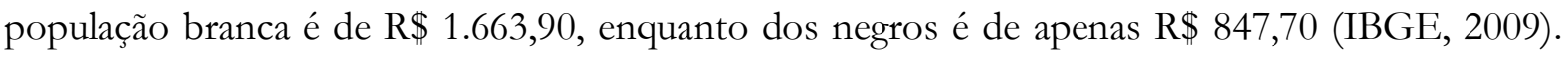
As únicas posições em que a taxa de negros é maior que a dos brancos são de analfabetismo: $27,4 \%$ contra 5,9\% dos brancos, desemprego e emprego informal: $24 \%$ contra $16,3 \%$ dos brancos (IBGE, 2012).

Ao analisarmos os dados do $3^{\circ}$ Levantamento Nacional sobre o Uso de Drogas pela População Brasileira (BASTOS, 2017), compreende-se que o perfil das mulheres que fazem o 
uso é composto majoritariamente por negras, pobres e na faixa etária entre 25 a 34 anos - fase reprodutiva feminina. Apesar das recomendações serem feitas tanto para maternidades públicas quanto para privadas, ao analisarem em quais maternidades ocorrem esses encaminhamentos compulsórios às Unidades de Reinserção Social (URS), nota-se que são as públicas que mais acionam a judicialização desses casos. E, de acordo com a Pesquisa Nacional por Amostra de Domicílios (PNAD, 2013), o perfil das usuárias atendidas nas maternidades públicas é composto por mulheres pretas e pardas, de baixa renda. Ou seja, a política de recolhimento dos bebês está voltada apenas para determinada parcela da sociedade, explicitando o caráter racista e classista das ações do Estado.

Os dados apontados anteriormente são um retrato das disparidades historicamente criadas pelo processo de escravização e perpetuadas pela ausência sistemática de políticas públicas por conta da abolição inconclusa (BURITY, 2006), que expôs essa parcela da população a um extermínio moral, cultural, social e demográfico, como também indica Abdias Nascimento, na obra O genocídio do negro brasileiro: processo de um racismo mascarado, de 1978. Essa "inclusão" lotada de restrições objetivas e subjetivas é parte de algo que o Brasil insiste em ocultar, mas não deixa de executar, o racismo estrutural (ALMEIDA, 2018).

Para Almeida (2018), esse fenômeno metódico de coerção que acomete a população negra está relacionado ao processo de desumanização dessas vidas e, que faz parte da expressão da violência estrutural reproduzida através da violência racial reproduzida nas ações das instituições de saúde mental, assistência social, judiciário, entre outros:

É no interior das regras institucionais que os indivíduos tornam-se sujeitos, visto que suas ações e seus comportamentos são inseridos em um conjunto de significados previamente estabelecidos pela estrutura social. Assim, as instituições moldam o comportamento humano, tanto do ponto de vista das decisões e do cálculo racional, como dos sentimentos e preferências. [...] A desigualdade racial é uma característica da sociedade não apenas por causa da ação isolada de grupos ou de indivíduos racistas, mas fundamentalmente porque as instituições são hegemonizadas por determinados grupos raciais que utilizam mecanismos institucionais par impor seus interesses políticos e econômicos. (ALMEIDA, 2018, p. 30).

Medeiros et al. (2015), por meio de entrevistas com mulheres que se encontravam em Comunidades Terapêuticas e Clínicas de Reabilitação nos Estados da Paraíba e Pernambuco, observaram que essas mulheres se enxergavam como perigosas e sem controle de si, reproduzindo o mesmo discurso que a sociedade lança sobre elas. Assim, essa visão que a sociedade e elas possuíam sobre si mesmas impactava diretamente na forma como se relacionavam com o cuidado e lidavam com as questões da vida. Nesse sentido, concluir previamente que essas mulheres serão incapazes de exercer a maternagem, sem compreender toda a complexidade que permeia essa relação e oferecer os meios necessários para a criação desse afeto e convívio, se configura como uma "mortificação do eu" que ocorre através das estratégias de contenção de sua subjetividade (GOFFMAN, 2008), de sua autonomia e potencialidade, assim as reduz a meramente usuárias de drogas.

Essa desumanização pode ser definida a partir do conceito de outridade, cunhado por Grada Kilomba (2010). Segundo a autora, a mulher negra é o "outro do outro", o que as colocam em um local de mais difícil reciprocidade. Assim, ao falar de mulheres negras que se 
encontram nas cenas de uso, podemos observar ainda outras questões que marcaram suas vidas como por exemplo, vida nas ruas, uso de drogas e passagem em sistema prisional - e as colocam em um lugar de maior desumanização e estigmatização (MALHEIRO, 2018, p.11)

Diante do exposto, podemos observar que essa prática de retirada de bebês tem muito mais a ver com o controle dos corpos que o Estado promove com a população negra e pobre, seja pela manicomialização, pelo encarceramento ou pela morte, do que com a suposta proteção ao bebê. De acordo com dados da Fundação de Assistência Social e Cidadania de Porto Alegre, o custo per capita de uma criança acolhida foi de três mil e quinhentos reais em 2015 (BELLOC et al., 2018). Nesse sentido, podemos apontar que a questão não é ausência de recursos e, sim, desinvestimento na vida dessas crianças e mães, o que perpetua a situação de vulnerabilidade em que se encontram as famílias negras, sobretudo monoparentais, no Brasil (NORO, 2021).

Por fim, destacamos a urgência da criação de políticas sociais que sejam norteadas pela estratégia de redução de danos (SANTOS et al., 2020), oferecendo uma rede de proteção social fortalecida, realizando a articulação entre os diversos serviços de saúde, assistência e justiça, e garantam o suporte necessário para mulheres negras exercerem o direito a maternidade de forma plena e autônoma, tendo pleno acesso aos serviços socioassistenciais - a medida em que seja seu desejo. Além da formação permanente dos profissionais da rede na temática do consumo de drogas por mulheres.

\section{Considerações Finais}

As análises que exploramos neste artigo nos permitiram refletir sobre o processo de desumanização sofrido cotidianamente por mulheres negras. Mesmo com tantos avanços conquistados pelo feminismo negro com relação aos direitos sexuais e reprodutivos, ainda há um longo caminho para percorrermos, especialmente no que se refere ao exercício da maternidade de mulheres que fazem uso prejudicial de drogas.

Como acompanhamos ao longo do texto, o discurso socialmente propagado sobre o mito do amor materno não abarca as mulheres negras. Pois, ora, quem poderia ser mais pecadora nessa sociedade do que um ser que, além de mulher e mãe, ainda tem um defeito de cor? ${ }^{11} \mathrm{E}$ se, além de tudo isso, ela ainda fizer uso de alguma substância psicoativa? Esse será o seu fim, no auge da desumanização, às margens de uma sociedade que insiste em só enxergá-las a partir do momento da gestação, quando então essa mulher deixa de ser invisível, para ser o visível estigmatizado e culpabilizado.

Ressaltamos que os questionamentos aqui levantados não esgotam o tema abordado, mas nos trazem subsídios para reflexão sobre a importância da construção conjunta de caminhos que se diferenciem da desumanização e da necropolítica que está posta para os corpos pretos, seja pelo extermínio quanto pela mortificação em vida. Além disso, trouxemos alguns elementos para pensarmos o quanto uma concepção conservadora sobre o uso prejudicial de álcool e/ ou drogas impacta diretamente a vida das mulheres negras, pobres, principalmente, as que estão em situação de rua.

\footnotetext{
11 Livro escrito por Ana Maria Gonçalves, em 2010, o romance histórico conta a vida de uma africana idosa, cega e à beira da morte, que viaja da África para o Brasil em busca do filho perdido há décadas. Ao longo da travessia, ela vai contando sua vida, marcada por mortes, estupros, violência e escravidão. Podemos facilmente fazer uma associação da situação da mulher retratada na obra com as mulheres/mães negras que sofrem violências cotidianas ainda na atualidade.
} 
Nesse sentido, nós, enquanto profissionais, devemos nos atentar a quais concepções estão orientando nossas práticas e intervenções. Uma vez que, o exercício profissional pode ter o poder de reprodução ou transformação da realidade a qual estamos inseridos. Nossa intervenção não pode ter como base medidas estigmatizantes e simplistas do senso comum, precisamos convocar essas mulheres para a construção de alternativas reais e palpáveis para a retomada de sua autonomia. Precisamos lutar para a criação de políticas protetivas para mães e filhos que os proporcionem condições favoráveis para a criação de um vínculo familiar, bem como uma rede de que estimule as potencialidades e o protagonismo dessas mulheres sobre suas próprias vidas. E, mais do que nunca, pautar novas possibilidades de cuidado, de afeto e de atenção à essas mulheres, que sejam plurais, criativas e realmente atendam as múltiplas demandas que estão postas no cotidiano dessas vidas, para que assim, mulheres negras possam um dia gozar plenamente do seu direito de serem mães.

\section{Referências}

ALMEIDA, S. O que é racismo estrutural? Belo Horizonte: Letramento, 2018.

ARAÚJO, V. S. de. Mães da resistência: um olhar sobre o papel do racismo no processo de adoecimento de mães militantes que perderam seus filhos para a violência de Estado. 2019. $130 \mathrm{f}$. Dissertação (Mestrado em Saúde Pública) - Escola Nacional de Saúde Pública Sergio Arouca, Fundação Oswaldo Cruz, Rio de Janeiro, 2019.

ASSIS, S.G.; FARIAS, L.O.P. (Orgs.). Levantamento Nacional das Crianças e Adolescentes em Serviço de Acolhimento. Hucitec: São Paulo, 2013.

BADINTER, E. Um amor conquistado: o mito do amor materno. Rio de Janeiro: Editora Nova Fronteira, 1985.

BARBOSA, R. H. S. Abuso de drogas e transtornos alimentares entre mulheres: sintomas de um mal-estar de gênero? Cadernos de Saúde Pública, Rio de Janeiro, v.33, n.1, 2017.

BASTOS, F. I. P. M. (Org.). III Levantamento Nacional sobreo uso de drogas pela população brasileira. Rio de Janeiro: FIOCRUZ/ICICT, 2017.

BELLOC, M. M.; CABRAL, K. V.; OLIVEIRA, C. S. A desmaternização das gestantes usuárias de drogas: violação de direitos e lacunas do cuidado. Saúde em Redes, v.4, p.37-49, 2018.

BRASIL. Estatuto da Criança e do Adolescente. Câmera dos Deputados, Lei n 8.069, de 13 de julho de 1990. DOU de 16/07/1990 - ECA. Brasília, DF.

BURITY, J. A. Desigualdades e a Abolição Inconclusa. Piracicaba: Revista Impulso, v. 17, n. 43, maio/ago. 2006, p. 21-31. 
CARNEIRO, M. E. R. Procura-se "preta, com muito bom leite, prendada e carinhosa": uma cartografia das amas-de-leite na sociedade carioca (1850-1888). 2006. 418 f. Tese (Doutorado em História) Universidade de Brasília, Brasília, 2006.

CNJ. Conselho Nacional de Justiça. Sistema Nacional de Adoção e Acolhimento. Brasil. 2021.

CRENSHAW, Kimberlé. Documento para o encontro de especialistas em aspectos da discriminação racial relativos ao gênero. Revista Estudos Feministas, v. 10, n. 1, p. 171-188, 2002.

CRESS. Bebês são retirados das mães nas maternidades de Belo Horizonte. Conselho Regional de Serviço Social 6 ${ }^{\mathbf{a}}$ Região (Minas Gerais). Belo Horizonte, 2017.

DAVIS, B. Falando da perda: hoje estou mal, espero que você entenda. In: WERNECK, J; MENDONÇA, M.; WHITE, E. O livro da saúde das mulheres negras: nossos passos vêm de longe. 2. ed. Rio de Janeiro: Pallas/Criola, 2006. p.103-110

DUARTE, M. J. O. Saúde mental, drogas e direitos humanos: por intervenções cidadãs aos usuários de drogas em contexto de internação compulsória. Revista Saúde em Debate, Rio de Janeiro, v. 37, dez. 2013.

HOFFMAN, K. M., S. Trawalter, J. R. Axt, e M. N. Oliver. Racial bias in pain assessment and treatment recommendations, and false beliefs about biological differences between blacks and whites. Proceedings of the National Academy of Sciences of the United States of America 113(6):4296-4301, 2016.

HOOKS, Bell. Sexism and the Black Female Slavw Experience. In: HOOKS, Bell. Ain't I a Woman. Black Woman and Feminism. London: Pluto Press, 1990.

FANON, F. Pele negra, máscaras brancas. Tradução: Renato da Silveira. Salvador: EDUFBA, 2008.

GONÇALVES, A. M. Um defeito de cor. Rio de Janeiro: Record, 2010.

GONZALEZ, L.; HASENBALG, C. Lugar de Negro. Rio de Janeiro: Marco Zero, 1982.

GONZALEZ, L. Racismo e sexismo na cultura brasileira. Revista Ciências Sociais Hoje, Anpocs, 2, 223-244, 1984.

IPEA. Instituto de Pesquisa Econômica Aplicada; Fórum Brasileiro de Segurança Pública. Atlas da violência, 2019.

IBGE. Instituto Brasileiro de Geografia e Estatística. Indicadores de cor ou raça, segundo a Pesquisa Mensal de Emprego. Março de 2009. Brasília, DF, 2009. 
IBGE. Instituto Brasileiro de Geografia e Estatística. Censo demográfico 2010: características gerais da população, religião e pessoas com deficiência. Rio de Janeiro, 2012.

IBGE. Instituto Brasileiro de Geografia e Estatística. Pesquisa nacional por amostra de domicílios: Tabela 262, população residente, por cor ou raça, situação e sexo. 2014.

KERGOAT, D. Relações sociais de sexo e divisão sexual do trabalho. In: LOPES, M. J. M.; MEYER, D. E.; WALDOW, V. R. (Org.). Gênero e Saúde. Porto Alegre: Artes Médicas, 1996. p.19-27.

KILOMBA, G. Memórias da Plantação: episódios de racismo cotidiano. Rio de Janeiro: Coboró, 2019.

LEAL, M. do C. et al. A cor da dor: iniquidades raciais na atenção pré-natal e ao parto no Brasil. Cadernos de Saúde Pública, v. 33, n. supl.1, 2017.

MÃE Preta. In: ENCICLOPÉDIA Itaú Cultural de Arte e Cultura Brasileiras. São Paulo: Itaú Cultural, 2021. Disponível em: http://enciclopedia.itaucultural.org.br/obra3242/mae-preta. Acesso em: 02 abr. 2021.

MALHEIRO, L.S.B. Tornar-se mulher usuária de crack: Trajetórias de vida, cultura do uso e política sobre drogas no Centro de Salvador, Bahia. In: Encontro da Rede Feminista Norte e Nordeste de Estudos e Pesquisas sobre Mulher e Relações de Gênero, n.20, 2018, Bahia.

MBEMBE, Achille. Necropolítica. 3. ed. São Paulo: n-1 edições, 2018.

MEDEIROS, K.T.; MACIEL, S.C.; SOUSA, P.F.; VIEIRA, G.L.S.; Vivências e Representações sobre o Crack: Um Estudo com Mulheres Usuárias. Psico-USF, v.20, p. 517-528, 2015.

MIOTO, R. C. T. Família e políticas sociais. In: BOSCHETTI, I. et.al (Orgs.). Política social no capitalismo: tendências contemporâneas. São Paulo: Cortez, 2008.

MOURA. C. E. M. Sojourner Truth. Géledes 2009. Disponível em: https://www.geledes.org.br/sojourner-truth/. Acesso em: 24 mai. 2021.

NORO, T. L. S. MULHERES EM CENA: Relato de experiência sobre um trabalho nas cenas de uso de drogas. Programa de Residência Multiprofissional em Saúde Mental. Instituto de Psiquiatria IPUB/UFRJ. 2021.

OIT. Manual de Capacitação e Informação sobre Gênero, Raça, Pobreza e Emprego: Módulo 11: monitoramento e avaliação de políticas públicas. Organização Internacional do Trabalho; Brasília: OIT, 2012. 
OLIVIO, M. C.; GRACZYK, R. C. Mulheres usuárias de crack e maternidade: breves considerações. In: II SIMPÓSIO GÊNERO E POLÍTICAS PÚBLICAS. 2011, Londrina, Anais..., Londrina, Universidade Estadual de Londrina, 18 e 19 de agosto de 2011

PASSOS, R. G. "E o lixa vai falar, e numa boa!". Revista Katalysis, Florianópolis, v.24, n. 2, p. 301-309, maio/ago. 2021.

PASSOS, R. G. Mulheres negras, sofrimento e cuidado colonial. Revista Em Pauta, n. 45, v. 18, p. $116-129.2020$.

PASSOS, R. G. Holocausto ou Navio Negreiro? Inquietações para a Reforma Psiquiátrica brasileira. Revista Argumentum. Vitória, v. 10, n. 3, p. 10-23, 23 dez. 2018.

PASSOS, R. G. "De escravas a cuidadoras": invisibilidade e subalternidade das mulheres negras na política de saúde mental brasileira. Revista O social em Questão, Ano XX, n. 38, mai/ago, 2017.

PASSOS, R. G. Entre o assistir e o cuidar: tendências teóricas no Serviço Social brasileiro. Revista Em Pauta, v.15(40), p.247- 260. 2017.

PASSOS, R. G. Trabalho, cuidado e sociabilidade: contribuições marxianas para o debate contemporâneo. Revista Serv. Soc. Soc., São Paulo, n. 126, p. 281-301, jun. 2016.

PEREIRA, M. O.; PASSOS, R. G. (Orgs.) Luta antimanicomial e feminismos: discussões de gênero, raça e classe para a Reforma Psiquiátrica brasileira. Rio de Janeiro: Autografia, 2017.

PEREIRA, M.O. Mulheres e reforma psiquiátrica brasileira: experiências e agir político. Tese (Saúde Mental) - Doutorado em Saúde Pública - Fundação Oswaldo Cruz, Rio de Janeiro, 2019.

SAFFIOTI, H. I. B. Gênero, Patriarcado e Violência. São Paulo: Fundação Perseu Abramo, 2004.

SAFFIOTI, H. I. B. O Poder do Macho. São Paulo: Moderna, 1987.

SANTOS, G.C.; CONSTANTINO, P.; SCHENKER, M.; RODRIGUES, L.B.; O consumo de crack por mulheres: uma análise sobre os sentidos construídos por profissionais de consultórios na rua da cidade do Rio de Janeiro, Brasil. Ciência \& Saúde Coletiva, v.25, p. 3795-2808, 2020.

SIMÕES-BARBOSA, R.H.; DANTAS-BERGER, S.M. Abuso de drogas e transtornos alimentares entre mulheres: sintomas de um mal-estar de gênero? Cadernos de Saúde Pública, Rio de Janeiro, v. 33, n.1, 2017.

SIQUEIRA, P. M. et al. Oh pedaço de mim, oh metade amputada de mim... Revista Saúde em Rede; 4(Supl.1), p 51-60, 2018. 